\title{
OSTEOPENIA LA COPIII CU SINDROAME DE MALABSORBȚIE
}

\author{
Tania Elena Rusu ${ }^{1}$, Evelina Moraru², Laura Bozomitu', \\ Dana Teodora Anton Păduraru ${ }^{1}$, Lucreția Anghel ${ }^{3}$, Aurica Rugină ${ }^{\mathbf{1}}$ \\ ${ }^{1}$ Disciplina Pediatrie, Universitatea de Medicină şi Farmacie ,, Gr. T. Popa “, Iaşi \\ ${ }^{2}$ Clinica II Pediatrie, Spitalul de Urgență pentru Copii „,Sfânta Maria“, Iaşi \\ ${ }^{3}$ Catedra de Medicină Internă, Universitatea de Medicină „,Dunărea de Jos “, Galați
}

\begin{abstract}
REZUMAT
Introducere. Sindroamele de malabsorbție au drept consecință perturbarea dezvoltării şi funcției normale a sistemului osos.

Obiective. Aprecierea densității osoase la copiii cu sindroame de malabsorbție. Analiza factorilor de risc pentru osteopenie. Evaluarea corelațiilor între osteopenie, markerii nutriționali şi markerii metabolismului osos.

Material şi metodă. 118 copii cu sindrom de malabsorbție de diverse etiologii, în principal boală celiacă (41 cazuri) şi fibroză chistică (14 cazuri). Densitatea osoasă a fost evaluată prin Ultrasonografie cantitativă (QUS) utilizând un Osteodensitometru Sunlight Omnisense Ultrasonometer 7000P. QUS a fost efectuată la radius (86 de cazuri) şi tibie (78 de cazuri). 25 hidroxivitamina D a fost evaluată la 10 cazuri prin metoda RIA. Analiza statistică a fost realizată utilizând SPSS for Windows.

Rezultate. Osteopenia a fost prezentă la 32\% dintre cazuri. Scăderea densitătii osoase la radius a fost asociată cu sindromul celiachiform. Osteopenia la tibie s-a asociat cu fibroza chistică. Osteopenia a fost mai frecventă la fete. Osteopenia s-a asociat cu durata bolii. Osteopenia nu s-a corelat cu BMI. Scorul Z la radius s-a corelat pozitiv cu nivelele fosfatazei alcaline, iar scorul Z la tibie cu colesterolemia. Scorul Z la tibie şi radius s-a corelat negativ cu valorile markerilor inflamatori. La copiii cu boală celiacă, valoarea anticorpilor anti-transglutaminază s-a corelat negativ cu scorul Z la radius şi tibie. Nivelele $25(\mathrm{OH})$ vitaminei D au fost deficiente la 8 copii şi insuficiente la 2 , dar valorile sale nu s-au corelat cu scorul Z la radius şi tibie. Semne clinice, biologice şi radiologice de rahitism au fost prezente la $35 \%$ dintre bolnavii cu osteopenie.

Concluzii. Osteopenia a fost prezentă la $1 / 3$ din bolnavii cu sindrom de malabsorbție din lotul studiat. $30 \%$ dintre bolnavi au avut semne clinice, biologice şi radiologice de rahitism. Valorile $25(\mathrm{OH})$ vitaminei D nu s-au corelat cu scorul Z. S-a observat o corelație negativă între parametrii osoşi şi markerii inflamației şi anticorpii anti-transglutaminază.
\end{abstract}

Cuvinte cheie: osteopenie, sindroame de malabsorbție, boală celiacă

\section{INTRODUCERE}

Osteopenia ( «gr. osteon» oston = os, penia = sărăcie, lipsă) defineşte o scădere a masei osoase şi se caracterizează din punct de vedere histologic printr-un deficit de țesut osos, iar radiologic prin semne de diminuare a densității osoase.

Evaluarea densităţii osoase la copil se impune ca explorare, deoarece de-a lungul vieții va exista acelaşi capital osos care a fost dobândit până la terminarea creşterii.

Principalele categorii de boli în care există risc de afectare a masei osoase în copilărie sunt bolile endocrine (deficitul de hormon de creştere, deficitul de hormoni sexuali, excesul de glucocorticoizi, excesul de hormoni tiroidieni), bolile reumatologice (artrita juvenilă idiopatică, lupusul eritematos sistemic), bolile cronice hepatice, bolile cronice renale, bolile inflamatorii cronice intestinale, sindroamele de malabsorbție, bolile hematologice (talasemia, siclemia, hemofilia, hemopatiile maligne), boli genetice diverse (afectarea genelor care codifică sinteza colagenului, afectarea receptorul pentru vitamina $\mathrm{D}$, boli de stocaj, homocistinuria, porfiria ş.a.).

Entităţile clinice care se manifestă prin diaree cronică, distensie abdominală şi falimentul creşterii, grupate ca sindrom de malabsorbție, includ printre numeroasele alterări homeostazice şi perturbarea dezvoltării şi a funcției normale a sistemu- 
lui osos $(1,2)$. Scăderea densității osoase asociată cu tablou clinico-biologic de rahitism (boală caracteristică osului în creştere) poate fi precoce şi constituie un marker de severitate a sindromului de malabsorbție. Principalii factori care contribuie la scăderea masei osoase în sindromul de malabsorbție sunt hipocalcemia (şi alte defíciențe minerale), hipovitaminoza D, deficitul nutrienților necesari pentru sinteza matricei osoase, inflamația cronică via citokinele pro-inflamatorii, dezechilibrul factorilor implicați în reglarea unității morfo-funcționale de bază a osului (Bone Multicellular Unit BMU), în funcţie de mecanismul, durata şi gravitatea entității clinice însoțite de sindrom de malabsorbție. De exemplu, în boala celiacă, alterarea masei osoase este consecința malabsorbției calciului, vitaminei D şi proteinelor ca urmare a distrucției enterocitelor, precum şi altor mecanisme, incluzând eliberarea de citokine proinflamatorii şi efectul lor de dezechilibrare a ciclului sinteză-resorbție osoasă din cadrul BMU, dezechilibre endocrine (Hiperparatiroidism secundar, dezechilibru androgeni-estrogeni), deficiențe nutriționale legate de regimul glutenopriv, efectul direct al anticorpilor anti-transglutaminază asupra osului, perturbări autoimune (diabet zaharat, tiroidită autoimună), factori genetici (polimorfismul genetic al genei Il-1b), tratamentul cu corticosteroizi.

\section{OBIECTIVE}

- Aprecierea incidenței osteopeniei la copiii cu sindroame de malabsorbție.

- Analiza factorilor de risc pentru osteopenie.

- Corelația osteopeniei cu markerii nutriţionali şi de metabolism osos.

\section{MATERIAL ŞI METODĂ}

Studiul prospectiv a cuprins 118 copii diagnosticați în Clinicile de Pediatrie ale Spitalului de Urgență pentru Copii „Sfânta Maria“, Iaşi, cu sindroame de malabsorbție de diverse etiologii. Majoritatea cazurilor au fost reprezentate de celiachie (41 de cazuri) urmate, în ordinea frecvenței, de sindrom de malabsorbție de etiologie neprecizată (16 cazuri), fibroză chistică (14 cazuri), intoleranță la proteina laptelui de vacă (11 cazuri), gastroduodenită eozinofilică ( 7 cazuri), hipogammaglobulinemie (6 cazuri), deficit selectiv de Imunoglobuline A (5 cazuri), lambliază (5 cazuri), sindrom celiachiform (3 cazuri), sindrom Ehlers Danlos (2 cazuri), deficit de Imunoglobuline G $(1 \mathrm{caz})$ şi rezecție intestinală (1 caz).
Aprecierea densității osoase s-a realizat prin Ultrasonografie cantitativă, utilizând un Osteodensitometru Sunlight Omnisense 7000P. Parametrii evaluați au fost viteza de transmitere a sunetului prin os (speed of sound SOS). Pornind de la valorile obținute la pacient, soft-ul Sunlight Omnisense calculează scorul Z. Un scor Z sub -1 a fost considerat osteopenie. Măsurătorile au fost efectuate la nivelul radiusului la 86 de cazuri şi la nivelul tibiei la 78 de cazuri.

Dozarea 25hidroxivitaminei D a fost posibilă la 10 cazuri prin metoda RIA. Deficitul de vitamina D este definit ca o valoare serică a acesteia de sub $20 \mathrm{ng} / \mathrm{ml}$. Valori între 21 şi $29 \mathrm{ng} / \mathrm{ml}$ sunt considerate insuficiență de vitamina $\mathrm{D}$.

Prelucrarea statistică s-a realizat cu programul SPSS for Windows.

$\mathrm{S}$-au realizat corelații ale scorului $\mathrm{Z}$ cu etiologia sindromului de malabsorbție, parametrii demografici: vârsta, sexul, cu durata bolii, indicii nutriţionali: IMC, parametrii biologici nutriționali: proteine totale serice, albumină serică, hemoglobină, colesterolemie, lipide totale serice, magneziemie, glicemie, sideremie; parametrii metabolismului fosfo-calcic: calciu total, calciu ionic, fosfor, fosfatază alcalină; markeri inflamatori: VSH, fibrinogen, valoarea anticorpilor anti-transglutaminază. Corelațiile s-au realizat prin testul Chi-pătrat, testul Mann-Whitney de comparare a rangurilor, testul $t$ de egalitate a mediilor, testul Anova, realizarea dreptelor de regresie şi calcularea coeficientului Pearson.

\section{REZULTATE}

Osteopenia a fost prezentă la $32,2 \%$ dintre cazuri, respectiv $38 / 118$ cazuri cu sindrom de malabsorbție de diverse etiologii.

În celiachie (lotul cel mai bine reprezentat numeric), osteopenia a avut o frecvență de 35,89\%, urmând fibroza chistică (jumătate din cazuri) şi sindroamele de malabsorbție cu etiologie neprecizată, gastroduodenită eozinofilică, sindrom celiachiform, sindrom Ehlers Danlos şi hipogamaglobulinemie. La copiii cu sindrom postgastroenteritic, osteopenia a fost absentă (Fig. 1).

Evaluarea relaţiei diferitelor diagnostice cu scăderea sub -1 a Scorului Z la radius relevă faptul că singurul diagnostic care s-a asociat semnificativ statistic la testul Chi-pătrat cu scăderea densității osoase la radius a fost cel de sindrom celiachiform $(p=0,047)$. Scorul Z la tibie scăzut sub $-1 \mathrm{~s}-\mathrm{a}$ asociat semnificativ din punct de vedere statistic doar cu diagnosticul de mucoviscidoză la testul Chi-pătrat $(\mathrm{p}=0,047)$. 


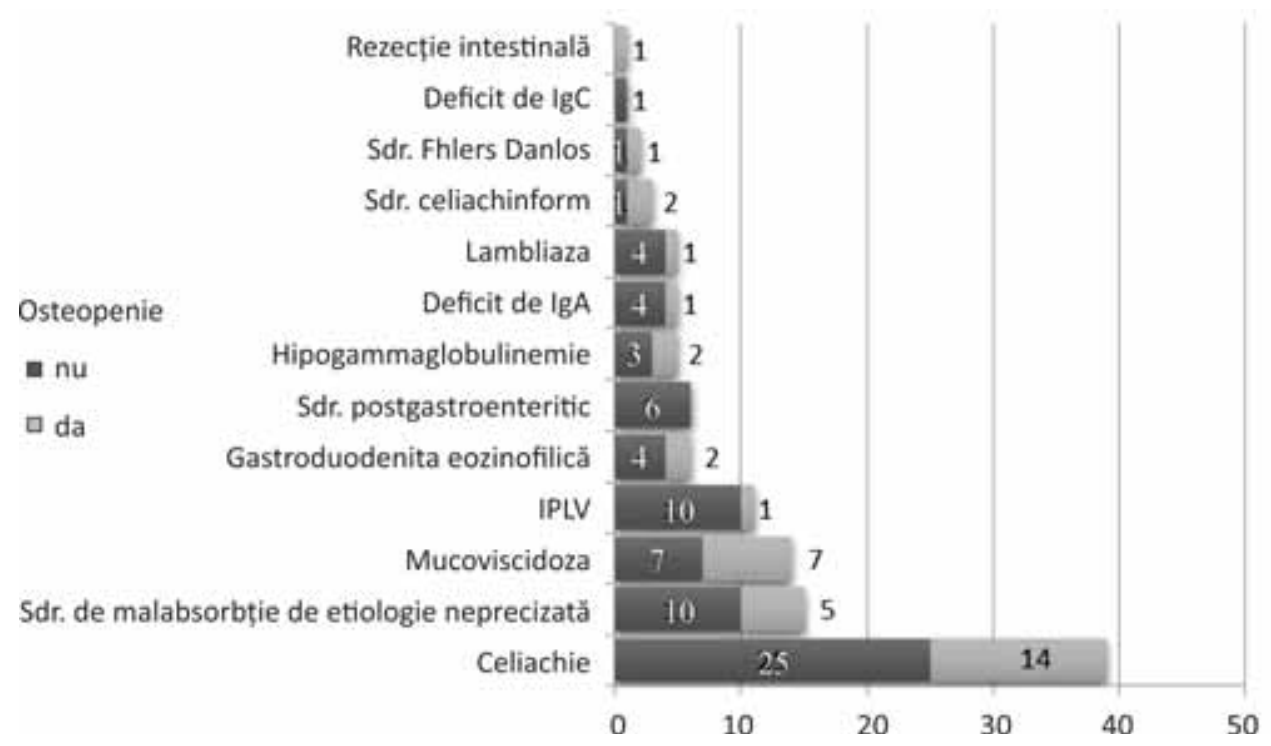

FIGURA 1. Prezența osteopeniei vs. etiologia sindromului de malabsorbție

$\mathrm{Nu}$ s-au înregistrat diferențe semnificative statistic între valorile scorurilor $\mathrm{Z}$ obținute la nivelul radiusului între diverse diagnostice. Valori semnificativ mai crescute ale scorului $Z$ la tibie față de restul grupului au fost obținute în sindromul postgastroenteritic. Valori semnificativ mai scăzute ale scorului Z la tibie față de restul lotului au fost obținute la bolnavii cu mucoviscidoză (Tabelul 1).

TABELUL 1. Compararea valorilor scorului $Z$ la radius şi la tibie în funcție de diagnostic prin testul $t$ de egalitate al mediilor

\begin{tabular}{|l|c|c|}
\hline DIAGNOSTIC & $\begin{array}{c}\text { Test t scor Z } \\
\text { radius }\end{array}$ & $\begin{array}{c}\text { Test t scor Z } \\
\text { tibie }\end{array}$ \\
\hline Celiachie & $\mathrm{p}=0,220$ & $\mathrm{p}=0,600$ \\
\hline $\begin{array}{l}\text { Sdr. de malabsorbție de } \\
\text { etiologie neprecizată }\end{array}$ & $\mathrm{p}=0,980$ & $\mathrm{p}=0,622$ \\
\hline Mucoviscidoză & $\mathrm{p}=0,154$ & $\mathrm{p}=0,024$ \\
\hline IPLV & $\mathrm{p}=0,439$ & $\mathrm{p}=0,683$ \\
\hline $\begin{array}{l}\text { Gastroduodenită } \\
\text { eozinofilică }\end{array}$ & $\mathrm{p}=0,325$ & $\mathrm{p}=0,711$ \\
\hline Sdr. postgastroenteritic & $\mathrm{p}=0,067$ & $\mathrm{p}=0,012$ \\
\hline Hipogammaglobulinemie & $\mathrm{p}=0,740$ & $\mathrm{p}=0,873$ \\
\hline Deficit de IgA & $\mathrm{p}=0,653$ & $\mathrm{p}=0,561$ \\
\hline Lambliază & $\mathrm{p}=0,613$ & $\mathrm{p}=0,052$ \\
\hline Sdr. Celiachiform & $\mathrm{p}=0,264$ & $\mathrm{p}=0,639$ \\
\hline Sdr. Ehlers Danlos & $\mathrm{p}=0,477$ & $\mathrm{p}=0,689$ \\
\hline Deficit de IgG & - & $\mathrm{p}=0,060$ \\
\hline Rezecție intestinală & 0,433 & \\
\hline
\end{tabular}

Osteopenia a fost mai frecventă la vârsta de preşcolar şi şcolar. Vârsta medie a cazurilor cu osteopenie a fost mai mare decât cea a bolnavilor cu masă osoasă normală (Fig. 2), diferență semnificativă din punct de vedere statistic la testul MannWhitney de comparare a rangurilor $(\mathrm{p}=0,015)$.

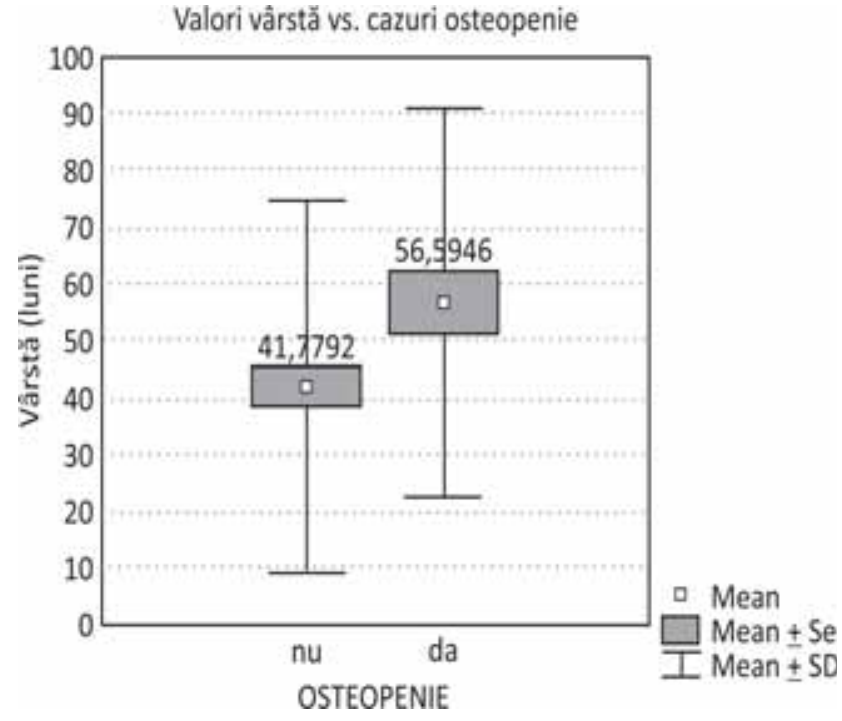

FIGURA 2. Valoarea medie a variabilei vârstă (luni) la cazurile cu şi fără osteopenie

Durata medie a bolilor însoțite de osteopenie a fost de 10,61 luni față de 7,13 luni a celor fără osteopenie, diferență nesemnificativă la testul MannWhitney $(\mathrm{p}=0,143)$.

În functie de sex, osteopenia a fost mai frecventă la fete cu o valoare procentuală de $36 \%$ față de $28 \%$ băieți $(p=0,377)$.

Nutriția deficitară, frecventă în sindroamele de malabsorbție prin suferința digestivă complexă şi perturbarea aportului, nu s-a asociat semnificativ statistic cu osteopenia, în condițile acestui studiu neomogen $(p=0,065)$. Valorile medii ale IMC la bolnavii cu osteopenie au fost 15,21 față de 14,26 la cei fără osteopenie.

Relația scorului $\mathrm{Z}$ la radius/tibie cu unii markeri ai răsunetului biologic al sindromului de malabsorbție s-a realizat prin coeficienții de corelație 
Pearson, testul ANOVA şi construcția dreptelor de regresie, rezultând următoarele corelaţii:

- Pozitivă între valorile Scorului Z la radius şi cele ale fosfatazei alcaline.

- Invers proporțională între valorile scorului Z la radius şi cele ale fibrinogenemiei

- Invers proporțională între valorile scorului Z la tibie şi fibrinogenemie.

- Moderată invers proporțională între scorul Z la tibie şi valorile VSH.

- Direct proporțională între valorile scorului Z la tibie şi valorile colesterolului total seric.

Global, osteopenia s-a asociat cu semne clinice de rahitism în 30\% dintre cazuri, markeri biologici ai rahitismului în $34,7 \%$ şi modificări radiologice la $35,7 \%$ dintre cazurile investigate.

Metabolitul 25 hidroxivitamina $\mathrm{D}$ a fost dozat la 10 bolnavi, rezultatele obținute fiind prezentate în Tabelul 2. Valorile au fost încadrate în nivele serice insuficiente de vitamina D la 2 cazuri şi deficit de vitamina $\mathrm{D}$ la 8 cazuri.

TABELUL 2. Valorile $25 \mathrm{OH}$ vitaminei $D$ la lotul de bolnavi cu sindroame de malabsorbție

\begin{tabular}{|l|c|c|}
\hline DIAGNOSTIC & 25 OH VITAMINA D & SCOR Z RADIUS \\
\hline Mucoviscidoza & Sub limita de detecție & 0,32 \\
\hline Mucoviscidoza & Sub limita de detecție & $-0,16$ \\
\hline $\begin{array}{l}\text { Sindrom de } \\
\text { malabsorbție }\end{array}$ & 19,89 & 1 \\
\hline Celiachie & 19,86 & 0,65 \\
\hline Celiachie & 17,68 & 0,21 \\
\hline Mucoviscidoza & 11,93 & $-1,06$ \\
\hline Celiachie & 26,99 & 1,54 \\
\hline Mucoviscidoza & Sub limita de detecție & $-0,5$ \\
\hline $\begin{array}{l}\text { Sdr. celiachiform } \\
\text { postlambliazic }\end{array}$ & 24,16 & 1,15 \\
\hline Celiachie & 18,41 & 3,84 \\
\hline
\end{tabular}

Evaluarea corelaţiei dintre valoarea anticorpilor anti-transglutaminază şi scorurile $Z$ la radius şi la tibie prin coeficienții de corelaţie Pearson şi testul ANOVA arată o corelație puternică invers proporțională între valorile anticorpilor anti-transglutaminază şi cele ale scorului $Z$ la radius şi o corelaţie moderată invers proporțională între valorile anticorpilor antitransglutaminază şi cele ale scorului Z la tibie.

\section{DISCUȚII}

Studiile privind densitatea osoasă la pacienții cu boală celiacă au raportat o incidență a scăderii masei osoase la $75 \%$ dintre pacienții nou diagnosticați, care nu se află sub regim glutenopriv $(3,4)$. În boala celiacă, distrucția mediată imun a enterocitelor conduce la scăderea suprafeței de absorbție, având drept consecință alterarea absorbției calciului, vitaminei D şi a proteinelor. Aceasta se reflectă în valorile serice reduse ale calciului, care are drept consecință un hiperparatiroidism reacțional $(5,6)$. Hiperparatiroidismul conduce la creşterea activității de resorbție osteoclastică şi amplificarea activităţii enzimei 1-hidroxilază renală, rezultând augmentarea sintezei metabolitului activ 1,25 dihidroxivitamina D. Stimularea absorbției intestinale a calciului de către 1,25 dihidroxivitamina $\mathrm{D}$ este ineficientă, deoarece enterocitele imature posedă nivele foarte scăzute de calbindin, proteină transportoare de calciu (5).

Scăderea nivelului seric a 25 hidroxivitaminei D poate fi datorată nu doar absorbției scăzute, ci şi scăderii aportului, precum şi timpului de înjumătățire plasmatic scăzut, dependentă de transformarea sa excesivă în 1,25 dihidroxivitamina $\mathrm{D}$ de către nivele serice crescute de PTH. Nivelele serice crescute ale 1,25 dihidroxivitaminei $\mathrm{D}$ au un efect nociv pe metabolismul osos, promovând resorbția osoasă $(5,6)$.

Prezența semnelor clinice, biologice şi radiologice de rahitism la aproximativ 35\% dintre bolnavii cu osteopenie sugerează că hipovitaminoza D şi hiperparatiroidismul reacțional sunt implicate în etiopatogenia osteopeniei la aproximativ 35\% din bolnavii $\mathrm{cu}$ osteopenie ai lotului studiat. Zanchi şi colaboratorii (2008) raportează prezența alterărilor biologice ale metabolismului calciului la 50\% dintr-un lot de 54 de bolnavi cu celiachie. Dintre aceştia, jumătate au avut osteopenie la osteodensitometria DEXA (7). Rezultatele obținute la lotul nostru au fost similare, $50 \%$ dintre cei 41 de bolnavi cu celiachie prezentând asocierea a două semne biologice de alterare a metabolismului fosfo-calcic şi din aceştia din urmă jumătate prezentând osteopenie la osteodensitometria QUS.

În ultima vreme, cercetările s-au axat pe stabilirea rolului patogenetic al citokinelor în afectarea osoasă din boala celiacă. Alterarea echilibrului osteosinteză osteoblastică/resorbție osteoclastică joacă un rol aparte în patogeneza osteopeniei din boala celiacă, existând nivele crescute ale citokinelor activatoare ale osteoclastelor (IL-1, IL-6, TNF $\alpha$ ), şi nivele scăzute ale citokinelor inhibitorii ale osteoclastelor (IL-18 şi IL-12) $(5,8)$.

Evidențierea corelației invers proporţionale ale valorilor scorului $\mathrm{Z}$ la radius şi tibie cu valorile Fibrinogenului şi VSH, pledează pentru rolul inflamației în etiopatogenia osteopeniei la o parte din bolnavii cu sindrom de malabsorbție luați în studiu. Bianchi şi colaboratorii (2008) subliniază rolul in- 
flamației în patogeneza alterărilor masei osoase din celiachie (9). Taranta şi colaboratorii (2004) evidențiază rolul activării osteoclastice de către cascada citokinelor proinflamatorii în osteopenia din boala celiacă (10).

Anticorpii antitransglutaminază tip Ig A acționează împotriva țesutului osos, titrul lor corelânduse cu afectarea densităţii osoase, ceea ce sugerează rolul lor în patogeneza osteopeniei din celiachie (11). Corelația invers proporțională puternică obținută între valorile anticorpilor anti-transglutaminază şi valorile scorului $Z$ la radius şi tibie susţine ipoteza implicării acestor anticorpi în alterarea masei osoase la lotul studiat.

Osteopenia, complicație comună a fibrozei chistice la copil, perturbă durabil calitatea vieții bolnavilor pe măsură ce speranța lor de viață creşte. Mai multe studii au documentat afectarea densităţii osoase, care s-a corelat cu severitatea bolii şi a afectării pulmonare, statusul nutriţional, vârsta, stadiul pubertar, existența şi durata terapiei cu glucocorticoizi, activitatea fizică (12-17). Osteopenia a fost evidenţiată la jumătate dintre bolnavii cu fibro- ză chistică luați în studiu, dimensiunea scăzută a lotului nepermițând realizarea de corelații statistice.

\section{CONCLUZII}

Sindromul de malabsorbție se însoțeşte de osteopenie la cel puțin $1 / 3$ din bolnavi $(32,2 \%)$. Asocierea semnelor clinice, biologice şi radiologice de rahitism la 30\% din bolnavii cu osteopenie susține impactul patogenetic al tulburărilor metabolismului fosfo-calcic.

Determinarea în dinamică a valorilor serice 25(OH)D, marker pentru evidențierea deficitului de vitamina $\mathrm{D}$, este utilă conducerii tratamentului la bolnavii cu sindroame de malabsorbție. Valoarea sa însă nu s-a corelat cu densitatea osoasă măsurată prin ultrasonografie cantitativă în acest studiu.

Corelaţia negativă a valorilor parametrilor ultrasonografici cu markerii inflamației şi valorile anticorpilor anti-transglutaminază impune efectuarea osteodensitometriei şi includerea osteopeniei ca martor al procesului inflamator cu mecanism imunologic. 